\title{
UPAYA MENINGKATKAN MINAT UNTUK MENABUNG PADA PT. BPR BATANG KAPAS
}

\author{
Sesri Wahyuni, Ratna Widayati \\ Akademi Keuangan dan Perbankan Padang \\ ratnawidayati@akbpstie.ac.id
}

\begin{abstract}
The purpose to know the development of the number of savings customers, and knowing the efforts made increase interest to save. Interest is an interest in one's feelings toward an object. The research method used is using direct research that is by doing direct object research so that the data obtained from the original source trusted by observation techniques, literature study and use descriptive analysis techniques. The growth of the number of savings customers from year to year continues to increase. So the number of customers who save at PT. BPR Batang Kapas also experienced a better increase. With the promotion of savings products to be socialized to places that have obtained permission, advertising in the form of brochures by coming to prospective customers directly, publicity that aims to maintain good relations with the community.
\end{abstract}

Keywords: Interest, Effort, Progress of Customer Number

\section{PENDAHULUAN}

Perkembangan dunia perbankan di Indonesia saat ini semakin kompetitif yang menuntut setiap bank untuk dapat mengolah dan melaksanakan manajemen secara lebih profesional.

Menurut Undang-Undang No.10 Tahun 1998 perubahan Undang-Undang No.7 Tahun 1992 Pasal 1 Tentang perbankan : Bank adalah badan usaha yang menghimpun dana dari masyarakat dalam bentuk simpanan dan menyalurkan kepada masyarakat dalam bentuk kredit dan dalam bentuk lainnya dalam rangka meningkatkan taraf hidup banyak rakyat.

Bank Perkreditan Rakyat (BPR) merupakan lembaga keuangan bank yang menerima simpanan dalam bentuk tabungan, deposito berjangka dan bentuk lainnya yang dipersamakan.

Seiring dengan perkembangan perbankan, banyak bank mulai bermunculan, salah satunya PT. Bank Perkreditan Rakyat Batang Kapas Pesisir Selatan adalah salah satu perusahaan perbankan yang dalam kegiatannya meliputi penghimpunan dana dari masyarakat dalam bentuk simpanan serta menyalurkannya dana dalam bentuk kredit kepada masyarakat sebagai penunjang kegiatan perekonomian masyarakat.

Menabung merupakan kegiatan menyisihkan sebagian uang belanja yang dimiliki untuk disimpan dengan tujuan untuk dana darurat dan untuk masa yang akan datang, pada intinya seseorang menabung adalah sebagai dana untuk jagajaga. hal tersebut bertujuan untuk menjalankan pola hidup hemat dan juga 
membangun karakter agar kedepannya tidak menghamburkan uang yang semestinya di terapkan sejak dini.

Kegiatan menabung yang sering digunakan orang untuk menyimpan uangnya dengan calengan, namun seiring perkembangan zaman maka cara itu dianggap kurang efektif dan menguntungkan karena kini sudah berkembang badan usaha yang bernama bank.

PT.BPR Batang Kapas mencoba meraba kembali dalam meningkatkan minat masyarakat untuk menabung, dengan memberikan kemudahan kepada masyarakat untuk menabung dan memberikan hal menarik lainnnya, salah satunya dengan tabungan bajapuik. Tabungan Bajapuik adalah Tabungan yang di jemput ke rumah-rumah warga seminggu sekali dari salah satu personil PT.BPR Batang Kapas.

Menurut Nofka Andika Haryas S.H, "Tabungan Bajapuik adalah salah satu langkah dari PT.BPR Batang Kapas, Untuk menanamkan kesadaraan menabung bagi sejumlah orang dimana budaya menabung telah mulai tergores zaman"

Berdasarkan uraian diatas, Penulis tertarik untuk melakukan penelitian dan pembahasan dalam tugas akhir yang berjudul "Upaya meningkatkan minat untuk menabung pada PT.BPR Batang Kapas "

Rumusan Masalah

Adapun perumusan masalah dalam penelitian tugas akhir ini yaitu bagaimana upaya meningkatkan minat untuk menabung pada PT. BPR Batang Kapas.

Tujuan Penelitian

Berdasarkan rumusan masalah, tujuan penelitian ini adalah untuk mengetahui upaya bank dalam meningkatkan minat menabung pada PT. BPR Batang Kapas.

Manfaat Penelitian

Ada beberapa manfaat yang dapat diperoleh dari penelitian ini yaitu:

1. Bagi penulis merupakan alat untuk mengembangkan ilmu pengetahuan yang penulis dapat selama bangku kuliah dan menambah pengetahuan penulis khususnya untuk meningkatkan minat untuk menabung.

2. Bagi PT. BPR Batang Kapas diharapkan bisa dijadikan bahan pertimbangan dalam menetapkan kebijaksanaan dalam meningkatkan minat untuk menabung.

3. Sumbangan ilmiah dalam dunia pendidikan bagi akademik.

\section{METODE PENELITIAN}

Dalam pengumpulan data dan bahan untuk melakukan penelitian ini, penulis menggunakan metode dengan dua cara sebagai berikut :

1. Studi Kepustakaan (Library Research)

Penelitian yang dilakukan ke perpustakaan beberapa buku-buku ilmiah dan tulisan-tulisan yang berhubungan dengan pembahasan yang dilakukan.

2. Studi Lapangan (Field Research)

Peninjauan langsung ke objek penelitian yang telah dipilih untuk meneliti hasil data primer. Penelitian langsung ke lapangan untuk melengkapi data yang penulis perlukan. Adapun cara riset lapangan adalah dengan mewawancarai pihak-pihak yang berkepentingan dalam hal ini adalah perusahaan atau instansi yang terkait. 


\section{LANDASAN TEORI}

\section{Sejarah Singkat}

Menyikapi arti penting sebuah bank dalam mendukung pertumbuhan ekonomi masyarakat desa, Bank Nagari Kabupaten Pesisir Selatan mendirikan beberapa buah BPR yang ditujukan untuk membantu masyarakat kecil, salah satunya PT. BPR Batang Kapas.

PT. BPR Batang Kapas termasuk salah satu BPR dari tujuh kelompok Bank Nagari yang diresmikan oleh Gubernur Sumatera Barat yaitu Bapak Zainal Bakar, SH yang dilaksanakan di PT. BPR Batipuh Padang Panjang, pada tanggal 19 februari 2001, sedangkan PT. BPR Batang Kapas sendiri diresmikan secara simbolis oleh wakil bupati, Bapak Nasrul Abit dan mulai beroperasi pada tanggal 22 Januari 2001. Dengan akte pendirian PT. BPR Batang Kapas yaitu Akta Notaris Syamsuhardi, SH di padang No.155 tanggal 15 Desember 2000 dengan pengesehan oleh Mentri Kehakiman dan Hak Azasi Manusia Republik Indonesia Nomor : C.2985 HT.01.01,TH.2001.

PT. BPR Batang Kapas yang berlokasi di Jl.Pasar Kuok Kec.Batang Kapas, Kab.Pesisir Selatan, lokasi tersebut strategis dekat dengan masyarakat.

Seiring dengan perubahan waktu maka pendirian Akte Notaris Syamsuhardi, SH di Padang No. 20 tanggal 11 Agustus 2008 dengan pengesahan oleh Mentri Hukum dan Hak Azasi Manusia Republik Indonesia Nomor : AHU71440.AH.01.02. Tahun 2008.

\section{Struktur Organisasi}

Struktur organisasi merupakan hal yang sangat penting, karena didalam struktur organisasi terlihat jelas pembagian wewenang, tugas dan tanggung jawab personil dalam perusahaan.

Pembagian tugas dan wewenang dari tiap peringkat organisasi pada PT. BPR Batang Kapas diatas adalah :

1. Rapat Umum Pemegang Saham (RUPS)

2. Dewan komisaris

3. Dewan direksi

4. Internal audit

5. Manajer marketing kredit

6. Manajer marketing dana

7. Manajer operasional

8. Marketing kredit

9. Marketing dana

10. Adm kredit

11. Pembukuan

12. Customer Service atau Adm. Tabungan dan Deposito

13. Teller 


\section{Ruang Lingkup Usaha PT. BPR Batang Kapas}

Adapun produk dari PT. BPR Batang Kapas itu sendiri adalah :

1. Menghimpun dana dari masyarakat dalam betuk tabungan dan deposito

a. Tabungan

1) Tami (Tabungan Kami)

Yaitu tabungan yang diperuntukkan untuk masyarakat baik dari penabung kecil sampai penabung besar, dengan ketentuan umum melampirkan kartu identitas/KTP, dan dengan setoran awal yang ringan minimal Rp. 25.000,- dan adm Rp. 2.500,-/3bln.

2) Tami Bajapuik

Yaitu Tabungan yang dijemput kerumah-rumah nasabah, tabungan bajapuik sangat memudahkan nasabah yang tidak bisa atau tidak sempat ke bank untuk menyetor tabungan, dengan ketentuan melampirkan kartu identitas/KTP dengan saldo awal minimal Rp. 10.000,- dan penyetoran berikutnya dengan saldo minimal Rp. 5.000,- serta dengan adm Rp. 2.500,-/3bln.

3) Puro Nagari

Yaitu tabungan semua lapisan masyarakat. Dengan melampirkan kartu identitas/KTP, dan saldo awal minimal Rp. 25.000,- dan saldo setelah pengambilan minimal Rp. 25.000,-

4) Tabungan Qurban

Yaitu tabungan yang membantu anda untuk mewujudkan untuk ikut berqurban.

b. Deposito (Simpanan Berjangka)

Deposito Berjangka adalah simpanan pihak ke-3 pada BPR yang penarikannya hanya dapat dilakukan setelah jangka waktu tertentu menurut perjanjian pihak ke-3 dengan pihak BPR, antara lain : jangka waktu 1 bulan, 3 bulan, 6 bulan dan 12 bulan, tingkat suku bunga tertinggi yaitu 9,5\% sesuai dengan suku bunga yang ditetapkan oleh Lembaga Penjamin Simpanan (LPS).

2. Menyalurkan dana dalam bentuk kredit

Adapun jenis-jenis kredit yang ada di PT. BPR Batang Kapas berdasarkan kegunaanya yaitu :

a. Kredit Usaha Kecil Informal (KUKI)

b. Kredit Berbagai Guna Pinjaman (KBGP)

c. Kredit Pengolahan Usaha Pertanian, Perkebunan dan Peternakan (KPUP3)

d. Kredit Pemberdayaan Ekonomi Masyarakat (KPEM)

e. Kredit Jaminan Deposito ( KJD)

f. Kredit Cicilan uang (KCU)

g. Kredit Usaha Produktif (KUP) 


\section{ANALISA DAN PEMBAHASAN}

Dalam analisa upaya meningkatkan minat untuk menabung PT. BPR Batang Kapas melakukan langkah langkah sebagai berikut:

1. Syarat-syarat Pembukaan Rekening Tabungan Pada PT. BPR Batang Kapas

a. Melampirkan fotocopy KTP

b. Melampirkan fotocopy KK (kartu keluarga)

c. Akta bagi mahasiswi yang belum punya KTP

d. Pembukaan rekening dilakukan langsung di PT. BPR Batang Kapas

e. Mengisi dan menandatangani formulir pembukaan rekening.

f. Saldo awal Rp. 25.000,-

Pembukuan rekening tabungan bagi masyarakat yang berusia 17 tahun keatas dapat melampirkan fotocopy KTP, masyarakat yang telah berkeluarga bisa melampirkan fotocopy KK, dan pelajar yang belum mempunyai KTP bisa melampirkan Akta Kelahirannya, hal ini bertujuan untuk mempermudah kelancaran pembukuan rekening tabungan dengan setoran saldo awal tidak membebankan masyarakat senilai RP. 25.000,-

2. Perkembangan Jumlah Tabungan Masyarakat Pada PT. BPR Batang Kapas Tahun 2013-2017

Bank BPR bertugas memberikan pelayanan kepada masyarakat serta menghimpun dana dalam bentuk tabungan dan deposito. Untuk mengetahui perkembangan jumlah tabungan masyarakat pada PT. BPR Batang Kapas tahun 2013 -2017, dapat dilihat pada tabel beikut:

Laporan Rincian Posisi Simpanan PT.BPR Batang Kapas

Tahun $2013-2017$

\begin{tabular}{|c|c|c|}
\hline Tahun & Jumlah rekening & ( RP ) \\
\hline 2013 & 7.486 & 4.431 .310 .996 \\
\hline 2014 & 7.981 & 4.302 .573 .282 \\
\hline 2015 & 8.612 & 5.703 .189 .217 \\
\hline 2016 & 8.972 & 6.006 .818 .980 \\
\hline 2017 & 9.415 & 6.570 .679 .402 \\
\hline
\end{tabular}

Sumber data : PT. BPR Batang Kapas

Berdasarkan tabel diatas dapat dilihat bahwa jumlah tabungan pada PT.BPR Batang Kapas terus meningkat pada tahun 2013 terdapat jumlah rekening sebanyak 7.486 dalam jumlah rupiahnya sebesar Rp. 4.431.310.996. Sedangkan lihat pada tahun 2014 jumlah rekening yang ada pada PT.BPR Batang Kapas mengalami sedikit peningkatan dengan jumlah rekening yaitu 7.981 dan dalam rupiahnya sebesar Rp. 4.302.573.282.

Pada Tahun 2015 posisi simpanan yang ada di PT. BPR Batang Kapas dengan jumlah rekening sebanyak 8.612 mengalami peningkatan dari tahun sebelumnya yang terdapat dalam rupiahya sebesar Rp. 5.703.189.217.

Pada Tahun 2016 jumlah rekening yang ada pada PT.BPR Batang Kapas mengalami peningkatan dari tahun sebelumnya dapat dilihat dari jumlah rekening sebanyak 8.972 dan yang terdapat dalam rupiahnya Rp. 6.006.818.980. 
Pada Tahun 2017 laporan posisi simpanan PT. BPR Batang Kapas mengalami jauh meninggkatnya dari tahun-tahun sebelumnya dilihat dari jumlah rekening terdapat 9.415 sedangkan dalam rupiahnya Rp. 6.570.679.402. Peningkatan jumlah tabungan ini adalah dari usaha yang dilakukan PT. BPR Batang Kapas dalam meningkatkan minat menabung.

3. Upaya Meningkatkan Minat Untuk Menabung Pada PT. BPR Batang Kapas

Dalam upaya meningkatkan minat untuk menabung PT. BPR Batang Kapas melakukan langkah-langkah sebagai berikut :

a. Melakukan promosi

Promosi merupakan cara untuk memperkenalkan produk yang dimiliki oleh PT. BPR Batang Kapas kepada masyarakat. Promosi yang dilakukan yaitu turun kelapangan secara langsung dengan mempromosikan produkproduk yang ada di PT. BPR Batang Kapas. Promosi ini bertujuan untuk menarik minat nasabah agar jumlah nasabah semakin meningkat pada bank tersebut, dan hal ini berguna menambah keuntungan serta berpengaruh baik dalam kelangsungan perkembangan bank tersebut dimasa akan datang.

Menawarkan berbagai produk tabungan dengan cara promosi bertujuan agar para calon nasabah lebih mengetahui apa saja produk yang ada pada bank tersebut, serta berguna untuk menarik perhatian para calon nasabah mengenai keunggulan produk yang ada pada PT. BPR Batang Kapas. Salah satu produk yang ditawarkan pada PT. BPR Batang Kapas adalah produk tabungan bajapuik dengan adanya tabungan bajapuik bisa mempermudah nasabah untuk menabung, sehingga menjadi daya tarik para calon nasabah untuk mau menyimpan dananya pada PT. BPR Batang Kapas.

b. Memberikan kemudahan dalam menyimpan dana di PT. BPR Batang Kapas dengan setoran awal minimal sebesar Rp.25.000,-. Dengan adanya kemudahan ini para calon nasabah akan tertarik untuk menabung pada PT. BPR Batang Kapas karna setoran awal yang tidak terlalu tinggi, serta tidak terlalu memberatkan para calon nasabah yang akan menabung pada PT. BPR Batang Kapas dengan setoran awal minimal Rp. 25.000,-.

c. Simpanan nasabah yang ada di PT. BPR Batang Kapas di jamin oleh LPS (lembaga penjamin simpanan). LPS berfungsi sebagai penjamin simpanan nasabah. Dengan adanya LPS pada PT. BPR Batang Kapas akan memberikan kepercayaan pada para calon nasabah bahwa dananya akan terjamin aman pada PT. BPR Batang Kapas, sehingga adanya LPS akan menambah kepercayaan para calon nasabah serta meyakinkan para calon nasabah bahwa dana yang akan disimpan atau di himpun pada PT. BPR Batang Kapas terjamin aman.

d. Pelayanan prima

Pada hakikatnya, pelayanan prima adalah salah satu usaha yang dilakukan bank untuk melayani nasabah dengan sebaik-baiknya, sehingga dapat memberikan kepuasan kepada para nasabah dan memenuhi kebutuhan 
serta keinginan nasabah, baik yang berupa produk barang, ataupun jasa yang diberikan, khususnya pada PT. BPR Batang Kapas.

Pada PT. BPR Batang Kapas pelayanan prima merupakan salah satu pelayanan yang dilakukan dalam melayani nasabah sebaik-baiknya, sehingga nasabah tersebut merasa puas, dengan pelayanan yang ada pada PT. BPR Batang Kapas. Salah satu contoh pelayanan prima yang diterapkan di PT. BPR Batang Kapas yaitu ketika nasabah memasuki bank, satpam akan menyapa dan bertanya, lalu satpam akan menunjukkan kepelayanan yang nasabah butuhkan, seperti ke teller bank, selanjutnya pihak teller akan menyapa kembali dan memberikan pelayanan, setelah pelayanan selesai pihak teller akan bertanya kembali, apakah ada lagi yang dibutuhan nasabah tersebut.

\section{PENUTUP}

\section{Kesimpulan}

Berdasarkan hasil analisis pada bab sebelumnya bahwa penelitian yang dapat ditarik kesimpulan sebagai berikut:

1. Terjadi peningkatan tabungan dari tahun 2013 sebesar Rp. 4.431.310.996. Pada tahun 2014 sebesar Rp. 4.302.573.282. Pada Tahun 2015 sebesar Rp. 5.703.189.217. Pada Tahun 2016 sebesar Rp. 6.006.818.980. dan Pada Tahun 2017 sebesar Rp. 6.570.679.402.

2. Upaya yang dilakukan oleh PT.BPR Batang Kapas meliputi :

a. Melakukan Promosi secara langsung ke lapangan dengan mempromosikan produk-produk yang ada di PT. BPR Batang Kapas. Menawarkan berbagai produk tabungan yang ada di PT. BPR Batang Kapas.

b. Memberikan kemudahan dalam pembukaan rekening baru dengan setoran awal sebesar Rp. 25.000,-

c. Pelayanan prima yang dilakukan dalam melayani nasabah sebaik-baiknya, sehingga nasabah tersebut merasa puas.

\section{Saran}

PT. BPR Batang Kapas harus lebih mengembangkan produk dan kualitas pelayanan jasa nya, agar meningkatnya jumlah nasabah yang menabung dari tahun ketahun, dan bisa menjadi lembaga perbankan yang dipercaya oleh masyarakat setempat, serta mampu berkontribusi di dunia perbankan.

\section{UCAPAN TERIMA KASIH}

Puji dan syukur kita panjatkan atas kehadiran Allah SWT, atas berkat rahmat dan karunia-Nya yang senantiasa dilimpahkan kepada kita semua. Sholawat dan salam semoga tercurahkan pada Nabi Muhammad SAW yang telah menyampaikan risalah dan syariat islam kepada seluruh umat manusia. Dan terima kasih kepada dosen Ratna Widayati, SH,MH selaku dosen pembimbing yang telah bersedia untuk meluangkan waktu untuk membimbing, memeriksa serta memberikan arahan-arahan serta saran dalam penyusunan artikel ini, Kepada keluarga besar AKBP STIE "KBP" Padang, staf dosen dan karyawan yang telah banyak memberikan ilmu pengetahuan serta bantuan selama ini sehingga penulis bisa menyelesaikan artikel ini. Ayah Basri dan Ibu Salmaidar tersayang, yang 
selalu mendoakan dan memberikan dukungan baik moril maupun materil kepada penulis.

\section{DAFTAR PUSTAKA}

Budiasih, Y. (2012). Struktur Organisasi, Desain Kerja Dan Pengaruhnya Terhadap Produktivitas Karyawan, 1(2).

Handri, M. H., \& Fernos, J. (2019). Pengaruh Suasana Toko Dan Lokasi Terhadap Minat Beli Konsumen Pada Mini Market Xmart Ulak Karang Padang. https://doi.org/10.31227/osf.io/qbze5

Hidayati, R. R., \& Marlius, D. (2018). Aktivitas Promosi Dalam Meningkatkan Dana Pihak Ketiga Pada PT. Bank Perkreditan Rakyat (BPR) Batang Kapas Pesisir Selatan. https://doi.org/10.31227/osf.io/8dgqn

Imamah, N. (2012). Analisis Camel Untuk Mengukur Tingkat Kesehatan Bank Pt. Bpr Syariah Al-Mabrur Kabupaten Ponorogo Periode 2004-2008. Profit, 6 (2012, June), 70-84.

Marlius, D. (2017). Keputusan Pembelian Berdasarkan Faktor Psikologis Dan Bauran Pemasaran Pada PT. Intercom Mobilindo Padang. Jurnal Pundi. Volume 1. No. 1. Hal. 57-66. https://doi.org/10.31575/jp.v1i1.9

Marlius, D. (2016). Pengaruh Bauran Pemasaran Jasa Terhadap Minat Nasabah Dalam Menabung Pada Bank Nagari Cabang Muaralabuh. https://doi.org/10.31227/osf.io/vdqgx

Priyanti,Y. Susanti, F. Aziz, N. (2017). Minat Beli Konsumen Toko Sepatu Bata Dipasar Raya Padang Dilihat Dari Sikap Dan Iklan. Jurnal Pundi, Vol. 01, No. 02

Susanti, F. (2018). Faktor Faktor Yang Mempengaruhi Minat Beli Pada ECommerce Lazada.co.id (Studi Pada Mahasiswa Jurusan S1 Manajemen “STIE KBP" Padang). https://doi.org/10.31227/osf.io/um4yw

Yuvendri, R., \& Susanto, R. (2019). Meningkatkan Mutu Pelayanan Dalam Usaha Menghimpun Dana Masyarakat (Tabungan) Pada PT. Bank Perkreditan Rakyat Prima Mulia Anugrah Cabang Padang. https://doi.org/10.31219/osf.io/6prcd 